\title{
Er det virkelig farlig å kombinere metronidazol og alkohol?
}

\begin{abstract}
BAKGRUNN Det er vanlig praksis å advare mot inntak av alkohol (etanol) ved bruk av metronidazol på grunn av faren for disulfiramliknende (antabusliknende) effekt. I denne artikkelen undersøker vi om det er grunnlag for en slik advarsel.
\end{abstract}

KUNNSKAPSGRUNNLAG Artikkelen er basert på gjennomgang av relevant litteratur etter søk i PubMed. Det ble også utført søk i WHOs bivirkningsdatabase.

RESULTATER Verken in vitro-studier, dyrefors $ø k$, bivirkningsrapporter eller kliniske studier gir overbevisende holdepunkter for at det er disulfiramliknende interaksjoner mellom etanol og metronidazol.

FORTOLKNING Advarselen mot samtidig bruk av alkohol og metronidazol synes å bygge på laboratorieforsøk og enkelttilfeller hvor de rapporterte reaksjonene like gjerne kan skyldes etanol alene eller bivirkning av metronidazol. Klinisk relevant interaksjon mellom etanol og metronidazol er ikke bekreftet i nyere forskning.

Mange leger og farmasøyter advarer mot å innta alkohol (etanol) samtidig som man bruker metronidazol (Flagyl). Dette er i henhold til allment aksepterte forsiktighetsregler for å unngå en disulfiramliknende (antabusliknende) reaksjon.

Tetraetyltiuramdisulfid eller disulfiram ble syntetisert første gang av den tyske kjemikeren Grodzki i 1881. 20 år senere ble midlets egenskaper tatt $\mathrm{i}$ bruk for å akselerere vulkaniseringsprosesser i gummiindustrien (fig 1), og fra 1940-årene ble det brukt som et middel mot skabb. Den danske legen Erik Jacobsen og hans medarbeider Jens Hald fant ut at oksidasjonen av acetaldehyd, det første oksideringsproduktet av etanol, ble hindret av disulfiram. En form av disulfiram ble i 1952 patentert som antabus («anti abuse») (1-3).

Senere forskning har vist at disulfiram med metabolitter gir irreversibel hemming av enzymet acetaldehyddehydrogenase (ALDH), slik at den toksiske metabolitten acetaldehyd akkumuleres dersom man inntar etanol.

Aldehyddehydrogenasene tilhører en superfamilie av enzymer som bryter ned aldehyder (fig 2). Subfamilien ALDH1 spiller en viktig rolle innen embryogenese og utvikling ved å modifisere retininsyresignalisering. ALDH2 er et viktig enzym i nedbrytningen av alkohol. Rundt $50 \%$ av befolkningen i Nordøst-Asia er bærere av en genetisk ALDH2-variant som gir markert redusert evne til å metabolisere aldehyder, noe som gjør dem utsatt for disulfiramliknende symptomer ved ethvert inntak av etanol (4).

Acetaldehyd aktiverer mastceller slik at histamin frigis. Resultatet er ubehagelige symptomer som hudrødme, hjertebank, fluktuasjoner i blodtrykk, kvalme, oppkast, hodepine, synsforstyrrelser, forvirring og i alvorlige tilfeller sirkulatorisk kollaps $(4,5)$

Metronidazol er et mye brukt antibiotikum ved infeksjoner med protozoer og anaerobe bakterier. Både i preparatomtalen (6) og i Norsk legemiddelhåndbok (7) frarådes inntak av alkohol ved behandling med metronidazol. Ifølge standardkilden Stockleys Drug Interactions er interaksjonen mellom etanol og metronidazol et kontroversielt tema, med en rapportert insidens på mellom 0 \% og $100 \%$. På grunn av all usikkerheten anbefaler Stockleys Drug Interactions likevel at pasienter advares mot mulig ubehag ved bruk av alkohol og metronidazol samtidig. Reaksjonen beskrives som vanligvis mer ubehagelig og skremmende enn alvorlig, og den krever som regel ingen behandling (8).

I denne artikkelen ser vi nærmere på grunnlaget for å advare mot å kombinere metronidazol og alkohol.

\section{Kunnskapsgrunnlag}

Ved søk i PubMed med MeSH-termene «metronidazole AND disulfiram», «metronidazole AND ethanol» og «metronidazole AND alcoholism», uten tidsavgrensning, identifiserte vi 163 artikler. Ut fra tittel og sammendrag inkluderte vi ni artikler og et brev som vi vurderte til primært å omhandle og bringe ny kunnskap om eventuell interaksjon mellom etanol og metronidazol. Siste oppdaterte søk ble utført 22.4. 2014. Stockleys Drug Interactions om kefalosporiner (9) ble funnet frem separat. Alle inkluderte artikler ble lest i sin helhet. I tillegg søkte vi i Verdens helseorganisasjons bivirkningsdatabase med termen «disulfiram-like reaction» kombinert med legemidlet «metronidazole» 6.5. 2014.

\author{
Hilde Fjeld \\ RELIS Sør-Øst \\ og \\ Avdeling for smittevern \\ Oslo universitetssykehus
}

Guttorm Raknes

guttorm.raknes@gmail.com

RELIS Nord-Norge

Universitetssykehuset Nord-Norge

og

Nasjonalt kompetansesenter for legevaktmedisin Uni Research Helse

Bergen

Se også kunnskapsprøve

på www.tidsskriftet.no/quiz

> Se lederartikkel på side 1633

\section{HOVEDBUDSKAP}

Ifølge innarbeidet praksis advares pasienter som bruker metronidazol mot å innta alkohol på grunn av faren for en disulfiramliknende reaksjon

Tilgjengelig dokumentasjon tyder på at metronidazol ikke hemmer acetaldehyddehydrogenase slik disulfiram gjør

Kunnskapsgrunnlaget for å advare mot samtidig bruk av alkohol og metronidazol er svakt 


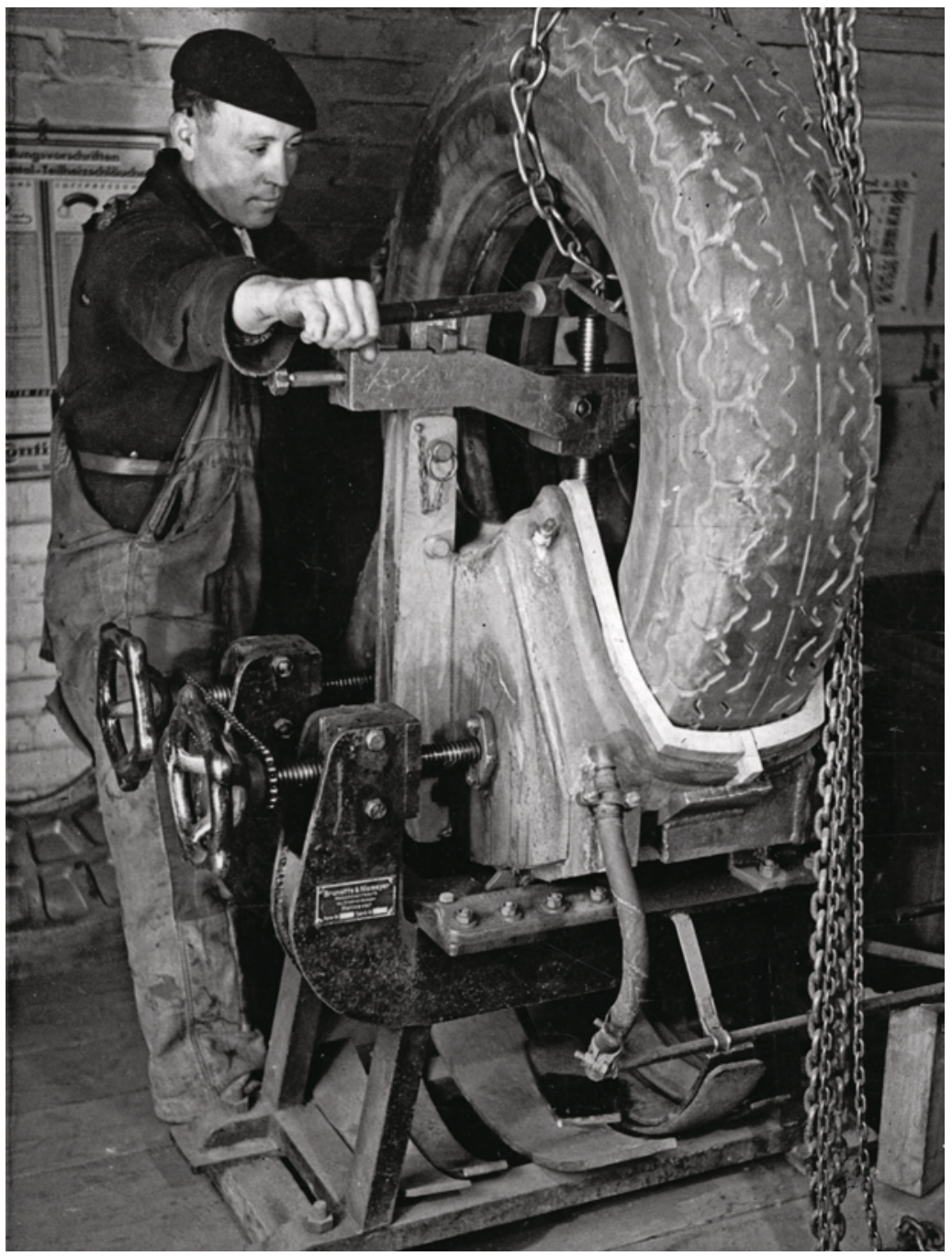

Figur 1 Disulfiram ble lenge brukt i gummiindustrien. Observasjoner av hvordan arbeiderne reagerte på alkohol er en del av forhistorien til legemidlet antabus. Foto: Bundesarchiv

Artikkelen er delvis basert på en ikkeoffentliggjort RELIS-utredning utført av forfatterne.

\section{Resultater}

Data fra laboratoriefors $ø$ k

I en artikkel i Nature fra 1967 ble metronidazol funnet å være en ikke-kompetitiv hemmer av ALDH i lever ved in vitro-testing på human lever. Konsentrasjonen av metronidazol var 1,6 mmol/1. Forfatterne opplyser at én enkelt dose med $200 \mathrm{mg}$ metronidazol in vivo gir konsentrasjoner på ca. $5 \mu \mathrm{g} / \mathrm{ml}$, tilsvarende $0,03 \mathrm{mmol} / \mathrm{l}$. De konkluderer derfor med at det er usannsynlig at den observerte inhibisjonen in vitro vil være klinisk relevant med mindre legemidlet oppkonsentreres i leveren (10).

Forsøk i rotter som får metronidazol har ikke vist hemming av hepatisk ALDH (verken ALDH1 eller ALDH2) eller økt konsentrasjon av acetaldehyd $\mathrm{i}$ blod etter etanolinntak (11-13). I den ene studien ble det observert en doseavhengig økning av alkoholtoksisiteten ved en samtidig engangsadministrasjon av metronidazol. Forfatterne mente at muligens metronidazol (eller en metabolitt) har dempende effekter på sentralnervesystemet. Denne effekten ble ikke observert ved gjentatte administrasjoner av metronidazol (11).

Metronidazol økte acetaldehydkonsentrasjonen i tarmen hos rotter som var blitt kronisk behandlet med etanol. På bakgrunn av dette ble det blant annet spekulert i om histaminfrigjøring kunne skje på bakgrunn av økt acetaldehydkonsentrasjon i tarmen (12). I den nyeste studien ble det funnet at metronidazol hemmer alkoholdehydrogenase (ADH) i noen grad (13). Dette var ikke tilfellet i de tidligere studiene.

\section{Kliniske studier og bivirkningsrapporter}

Sent i 1960-årene var metronidazol ansett som en kur mot alkoholisme, også i Norge. Psykiateren Odd Lingjærde var blant dem som syntes det faglige grunnlaget for denne behandlingen var svakt (14).

To studier hvor metronidazol ble brukt som middel ved alkoholavvenning kan muligens forklare opprinnelsen til hypotesen om at det brukt sammen med alkohol gir en disulfiramliknende reaksjon.

Ifølge en pilotstudie med 26 pasienter fra 1966 så metronidazol ut til «konsistent å produsere en markert aversjon mot inntak av alkohol innen to uker hos dem som er godt motivert i sitt ønske om å stoppe drikkingen». Behandlingen ble vurdert som ikke-toksisk med en bred sikkerhetsmargin. De beskrevne bivirkningene var svært milde, og disulfiramliknende reaksjoner er ikke nevnt (15).

En artikkel fra 1969 i New England Journal of Medicine omhandler en randomisert, dobbeltblindet studie hvor 48 krigsveteraner som ble behandlet for alkoholavhengighet $\mathrm{i}$ institusjon fikk disulfiram $500 \mathrm{mg}$ daglig i en måned, deretter 250 mg daglig. Halvparten fikk også metronidazol $750 \mathrm{mg}$ daglig i en måned, deretter $250 \mathrm{mg}$ daglig. I artikkelen er det ikke oppgitt hvor lenge studien pågikk eller hvor mye alkohol studiedeltakerne drakk.

Fire av de første 20 studiedeltakerne som fikk både disulfiram og metronidazol utviklet akutt psykose, mens det var ingen tilfeller blant dem som fikk disulfiram og placebo. Forfatterne konkluderer med at dette skyldes kombinasjonen av disulfiram og metronidazol og diskuterer ikke om hendelsene kan ha andre forklaringer (16). De kommenterer senere at metronidazol alene ikke er rapportert å gi psykiatriske bivirkninger $\mathrm{i}$ doser på opptil 2400 mg (17).

Forfatterne av en oversiktsartikkel fra år 2000 identifiserte seks kasuistikker med beskrivelser av alvorlige etanol-metronidazolinteraksjoner. Felles for alle sykehistoriene var at den disulfiramliknende effekten av metronidazol ble tatt for gitt, slik at man ikke vurderte andre forklaringer på pasientenes symptomer. I to av kasuistikkene kunne etanol alene forklare reaksjonen, mens i de øvrige fire kunne symptomene knyttes til bruk av andre legemidler, postoperativ tilstand og/eller annen sykdom (18).

I en finsk studie ble 12 friske frivillige unge menn randomisert til metronidazol $200 \mathrm{mg}$ eller placebo tre ganger daglig i fem dager før de ble eksponert for 0,4 g etanol per kilo kroppsvekt. Det ble ikke observert noen forskjell i etanolkonsentrasjon, og det var ikke målbare acetaldehydkonsentrasjoner hos noen. Det var heller ikke noen forskjell i puls, blodtrykk eller ansiktstemperatur etter inntak av alkohol. Ingen egenrapporterte subjektive plager som hodepine, kvalme, dyspné eller svimmelhet ble registrert i noen av gruppene (19).

I Verdens helseorganisasjons internasjo- 
nale bivirkningsdatabase foreligger det et 20-talls rapporter fra de siste 22 årene hvor kombinasjonen metronidazol og etanol/alkohol er mistenkt som årsak til disulfiramliknende reaksjon (20). Opplysninger om bruk av andre legemidler og sykdommer, vurdering av årsak eller sannsynlighet for sammenheng mellom bivirkningen og legemiddelbruken er mangelfull i dette materialet. Tallene sier heller ikke noe sikkert om frekvensen av de meldte bivirkningene.

WHO understreker at datauttrekk fra bivirkningsdatabasen ikke representerer WHOs offisielle syn og at dataene ikke er homogene med tanke på innsamling gjennom spontanrapporteringssystemet eller dokumenterer noen sikker sammenheng mellom det aktuelle legemidlet og bivirkningen.

\section{Diskusjon}

Dokumentasjonen på den disulfiramliknende effekten av metronidazol er svak. I artikkelen hvor metronidazol ble funnet å være en ikke-kompetitiv hemmer av ALDH $i$ lever ved in vitro-testing med human lever, var metronidazolkonsentrasjonene titall ganger høyere enn forventet terapeutisk konsentrasjon (10). I nyere dyreforsøk (12, 13) og en klinisk studie (19) har man ikke kunnet påvise at metronidazol hemmer aldehyddehydrogenase. Det er heller ikke dokumentert at bruk av metronidazol sammen med etanol gir uakseptable bivirkninger.

I den kliniske studien ble det riktignok gitt $200 \mathrm{mg}$ metronidazol tre ganger daglig, noe som er lavere enn vanlige terapeutiske doser (opptil $2000 \mathrm{mg}$ daglig for voksne) (6).

Med tanke på at metronidazol er et svært vanlig medikament, samtidig som at den disulfiramliknende interaksjonen med etanol har vært fryktet og velkjent, er antallet bivirkningsmeldinger overraskende lavt. Det er vanskelig å trekke konklusjoner ut fra denne type tall, og vi kan ikke utelukke at bivirkningen har vært ansett som så vanlig at interessen for å melde har vært liten.

En del av symptomene som mistenkes for å være disulfirameffekt, kan være bivirkninger av metronidazol, uavhengig av etanolinntak. Eksempler på kjente bivirkninger av metronidazol er kvalme, brekninger, smaks- forandringer, angioødem, krampeanfall, hodepine, svimmelhet, encefalopati (f.eks. forvirring), forbigående synsforstyrrelser og feber (6)

Sykdom, etanol alene eller etanoluavhengige bivirkninger av metronidazol kan være forklaringer på mistanken om disulfiramliknende effekter. Vi kan ikke utelukke at spesielle genmutasjoner vil føre til andre metabolismemønstre. Vi kan heller ikke utelukke at meget høye konsentrasjoner av metronidazol vil kunne hemme ALDH, men dette bør testes med oppdaterte metoder.

\section{Eksempler på andre}

mulige ALDH-hemmere

Kloramfenikol hemmer ALDH2 (13), men midlet er bare markedsført i ikke-systemiske formuleringer i Norge. Vi har ikke grunn til å tro at øyedråper og øyesalve gir disulfiramliknende reaksjoner.

Enkelte kefalosporiner som ikke markedsføres i Norge er rapportert å gi disulfiramliknende reaksjoner sammen med alkohol. Det er best dokumentert at reaksjonen oppstår med kefalosporiner som har en metyltetrazoltiolgruppe i tredjeposisjon på kefalosporinmolekylet (latamokscef, cefamandol, cefoperazon). Konsentrasjonen av acetaldehyd er påvist å kunne bli forhøyet hos rotter ved samtidig administrasjon av etanol og disse midlene (9).

To perorale diabetesmedikamenter som ikke markedsføres i Norge (klorpropamid og tolbutamid) er funnet å hemme ALDH2 i mus ved samtidig administrasjon med alkohol. Klorpropamid er kjent for å ha kraftigst hemming (7)

\section{Konklusjon}

Vi mener at det ikke er grunnlag for å hevde at metronidazol i klinisk relevante doser gir hemming av enzymet acetaldehyddehydrogenase slik at acetaldehyd akkumuleres dersom etanol inntas, slik disulfiram gjør. Vi vurderer at risikoen for interaksjoner mellom metronidazol og etanol tilsvarende disulfiram-etanol-interaksjoner er liten. Et forsiktig inntak av etanol sammen med metronidazol anser vi ikke som absolutt kontraindisert.
$\mathrm{ADH}$

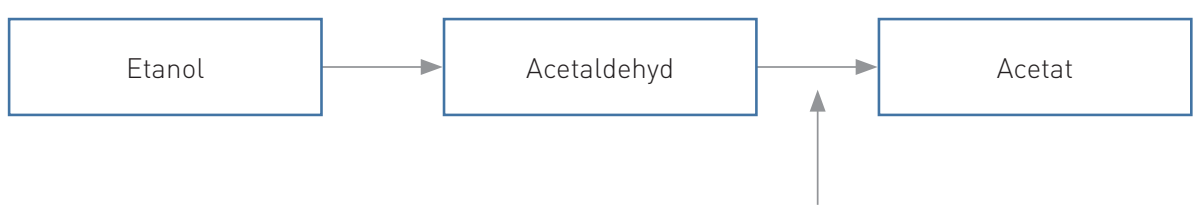

Disulfiram hemmer

denne reaksjonen

\section{Hilde Fjeld (f. 1976)}

er farmasøyt.

Forfatter har fylt ut ICMJE-skjemaet og oppgir ingen interessekonflikter.

\section{Guttorm Raknes (f. 1974)}

er spesialist i klinisk farmakologi.

Forfatter har fylt ut ICMJE-skjemaet og oppgir ingen interessekonflikter.

Litteratur

1. Suh JJ, Pettinati HM, Kampman KM et al. The status of disulfiram: a half of a century later. J Clin Psychopharmacol 2006; 26: 290-302.

2. Kragh $\mathrm{H}$. From disulfiram to antabuse: the invention of a drug. Bull Hist Chem 2008; 33: 82-8.

3. Vestergaard P. Psykofarmakologiens danske pionerer. Dansk medicinhistorisk årbog 2011; 39: 117-31.4.

4. Koppaka V, Thompson DC, Chen Y et al. Aldehyde dehydrogenase inhibitors: a comprehensive review of the pharmacology, mechanism of action, substrate specificity, and clinical application. Pharmacol Rev 2012; 64: 520-39.

5. Mørland J. Legemidler mot alkoholmisbruk. Tidsskr Nor Lægeforen 2006; 126: 3268-9.

6. Statens legemiddelverk. Preparatomtale (SPC) Flagyl. www.legemiddelverket.no/legemiddelsok (27.11.2012).

7. Norsk legemiddelhåndbok for helsepersonell. L1.2.14.1 Metronidazol. www.legemiddelhandboka. no/ (15.10.2013)

8. Baxter K. red. Stockleys Drug Interactions. Alcohol + Metronidazole and related drugs. www.medicinescomplete.com/ (19.12.2012)

9. Baxter K. red. Stockleys Drug Interactions. Alcoho + Cephalosporins. www.medicinescomplete.com/ (24.10.2012).

10. Edwards JA, Price J. Metronidazole and human alcohol dehydrogenase. Nature 1967; 214: 190-1.

11. Kalant H, LeBlanc AE, Guttman M et al. Metabolic and pharmacologic interaction of ethanol and metronidazole in the rat. Can J Physiol Pharmaco 1972: 50: 476-84

12. Tillonen J, Väkeväinen S, Salaspuro V et al. Metronidazole increases intracolonic but not periphera blood acetaldehyde in chronic ethanol-treated rats. Alcohol Clin Exp Res 2000; 24: 570-5.

13. Karamanakos PN, Pappas P. Boumba VA et al. Pharmaceutical agents known to produce disulfiram-like reaction: effects on hepatic ethanol metabolism and brain monoamines. Int J Toxicol 2007: 26: 423-32

14. Lingjærde O. Metronidazol (Flagyl) ved alkoholisme - et bomskudd? Tidsskr Nor Lægeforen 1971: 91: 1161.

15. Semer JM, Friedland $P$, Vaisberg $M$ et al. The use of metronidazole in the treatment of alcoholism: a pilot study. Am J Psychiatry 1966; 123: 722-4

16. Rothstein E, Clancy DD. Toxicity of disulfiram combined with metronidazole. N Engl J Med 1969; 280 : 1006-7.

17. Rothstein E, Clancy DD. Disulfiram-metronidazole. N Engl J Med 1969; 281: 331

18. Williams CS, Woodcock KR. Do ethanol and metronidazole interact to produce a disulfiram-like reaction? Ann Pharmacother 2000; 34: 255-7.

19. Visapää JP, Tillonen JS, Kaihovaara PS et al. Lack of disulfiram-like reaction with metronidazole and ethanol. Ann Pharmacother 2002; 36: 971-4.

20. Verdens helseorganisasjon (WHO). Bivirkningsdatabase. http://who-umc.org/DynPage.aspx (6.5.2014). 